\title{
Pedagogical issues in vocational teachers' learning: The importance of teacher development
}

\author{
Janet Hamilton Broad \\ UCL, Institute of Education, Department of Education, Practice and Society \\ London \\ UK \\ j.broad@ucl.ac.uk
}

\begin{abstract}
This chapter explores pedagogical approaches used by vocational teachers to capture new techniques, technology and knowledge developed through shared practice in workplaces. It argues that this is both a challenging and a problematic endeavour as teachers are situated in contexts removed from where vocational knowledge is developed. In addition, the nature of vocational knowledge which is complex, complicated and in constant motion and flux compounds the practical problems of collection and recontextualization of new techniques and innovations from workplaces to teaching environments. Examples are given from research findings of how vocational teachers overcome these challenges by utilizing professional development activities to capture new techniques, technologies and knowledge. These are discussed in order to shed light on the agentic action of vocational teachers and how they self-determine and self-select the activities they engage with. It is also shown why some activities are perceived by teachers to be valuable and why some hold little value. It is further shown that this is largely determined by the relational value of the activities engaged with and how relevant they are to the day-to-day practices of the individual teacher. The hidden nature of the pedagogy that teachers use is also illuminated. This exploration reveals the main characteristics of effective teacher pedagogy that are a) teacher agency; b) relational networks; and c) hidden pedagogical practices. The chapter concludes by arguing for new ways to both organize and conceptualize pedagogical approaches to the development of vocational teachers' occupational expertise.
\end{abstract}

Key words: vocational teachers; vocational knowledge; expertise; pedagogy; professional development; professional associations 


\section{Introduction}

In everyday workplaces, new approaches, techniques and technologies are developed, new ways of doing are adopted. It is therefore reasonable to say that vocational knowledge as it is applied and used in context is in a constant state of flux, it is temporal and has high levels of currency. This raises particular pedagogical issues for vocational teachers in how to keep abreast of new knowledge, skills and work processes. Once vocational practitioners have moved away from their occupation on a day-to-day basis to become vocational teachers, they are removed from where vocational knowledge is developed and so find it deeply problematic to ensure that their vocational expertise is maintained and refreshed. Regardless of these practical problems, the expertise and therefore the continuing professional development (CPD) of vocational teachers is central to high quality vocational education and training (VET) pedagogy. Within many of the debates concerned with high quality provision, are calls for highly experienced vocational teachers with a broad knowledge base and extensive expertise (see, inter alia Gamble 2013; Billett 2011). For Gamble (2013), vocational teachers require formal subject or technical knowledge, pedagogic expertise, and practical workplace experience. Wheelahan and Moodie (2011) in their report on Australian VET teachers also focus on the skills held by vocational teachers. Their view is that this rests on both initial training, mainly focusing on pedagogy and on continuing professional development to ensure currency in the occupational area is maintained. Congruent with these views, the focus of this chapter is the pedagogical approaches used in CPD activities by teachers to ensure that vocational expertise is maintained. The chapter argues that high quality vocational pedagogy offered by these teachers to vocational students, in the main, rests firmly on the vocational skills and expertise they hold.

Through exploring the interplay between teachers' professional development activities and subsequent enhanced student learning, a further and central argument of this chapter is that teachers are able, through CPD activities, to link occupational contexts to learning contexts so as to transport updated and fresh vocational expertise to share with their students. This central role of vocational teachers is described as

They reformulate vocational knowledge from work where it has mainly a productive function to a teaching-learning function, and they make this 
recontextualized vocational knowledge comprehensible to others - to students and novice practitioners or workers (Moodie and Wheelahan 2012: 17).

This also suggests that an important aspect of high quality VET provision is how a teacher's newly acquired vocational knowledge and skills is recontextualized from occupational sites to learning sites so as to provide rich and meaningful learning experiences for their students. It suggests that transportation of vocational knowledge across contexts is not a straightforward process.

Following this introduction, the chapter first examines currently accepted approaches to the CPD of teachers. From here, the theoretical positions on the nature of vocational knowledge, the development of expertise, models of professional learning, and how vocational teachers know are discussed. Within these discussions, the importance of context is also explored. The following section briefly explains the research methodologies adopted in a study of the professional development activities of vocational teachers, followed by a presentation of findings. These findings begin to shed light on how vocational teachers are able, through their development activities, to enrich the learning experience of their students. To further illuminate the approaches taken, the discussion exemplifies how, due to the very nature of vocational knowledge and practice, it is problematic and difficult for vocational teachers to maintain and enhance their vocational expertise once removed from vocational settings where it is developed and practised. The particular pedagogy of the professional development activities that vocational teachers engage with to manage these difficulties is explored and examined. It is argued that their CPD activities enable them to cross boundaries and to link the geographical and contextual sites where vocational knowledge is produced, to learning sites where it is shared with vocational students. Within this process, they recontextualize this new and refreshed knowledge and so enhance the curriculum offered to their students through richer learning experiences.

\section{The continuing professional development of teachers: A brief exploration of models}


Effective pedagogy within accepted approaches to vocational teachers' CPD is problematic to identify as whilst there is a relatively wide and mature body of literature on school teachers' professional development, post qualification, relatively, there is paucity on that of vocational teachers. However, whilst the literature focused on school teachers is not directly transferable in all instances, it can shed light on what works generally for teachers in their developmental activities. Suggested within this literature is a duality of approach which tends towards conceptualizing professional learning as knowledge transmission or alternatively, as collaborative and more social approaches. The literature suggests that collaborative approaches have long been recognized as being effective by providing the richest opportunities (see for example, Goodson and Hargreaves, 1996; Hargreaves, 1994). In their study, Hodkinson and Hodkinson (2005), found that high levels of collaboration bring an additional dimension to learning. It is richer and not bounded by notions of formal learning. Learning is informal and on-going whenever teachers are together through discussions, consultations, and sharing of materials and ideas.

In contrast, Day (2002) has argued for a more individualistic model of reflective practice and suggests that the normal CPD offer to teachers was through narrowly conceived 'training' models, implemented for external compliance requirements. More recently, Day (2017) suggests that the application of competency-based approaches, in the form of professional standards for teachers, atomizes knowledge and skills. He argues that any professional development activities for teachers must provide opportunities for deep learning and take account of the individual motivations of teachers.

Turning to the CPD of vocational teachers, Andersson and Köpsén (2015), drawing on the concept of dual professional identity (for an example of this within the English vocational education system, see, Orr and Simmons, 2010), argue that to be knowledgeable about their subject (occupation), requires them to have a distinct vocational identity that must be current and thus maintained. In order to do this, vocational teachers need to continue to have contact with their original occupational field and be active participants within it. This appears to suggest that vocational teachers are best served in their professional development by returning in some way to their original occupation. This further suggests that they will meet and work in collaborative and informal ways with those still working within the original occupation. However, the actual activities and thus the pedagogical approach that vocational 
teachers engage with through collaborative learning to maintain their vocational identity are problematic to easily identify. A comparative study by Lloyd and Payne (2012) sheds some light on this and they identified three ways in which hairdressing teachers maintain and develop their occupational expertise. These were, through working occasionally in a friend's salon, by suppliers of hairdressing products running workshops in the college salons and, through collaborative learning within the college by sharing ideas and reflecting on practice.

This short review of pedagogy within approaches to teachers' CPD suggest a duality of approach, either through knowledge transmission and individualist, or, through collaborative and more social approaches. It begins to suggest that the more collaborative approaches are more effective. The following section offers a theoretical exploration.

\section{Understanding vocational knowledge: the interplay with teacher expertise and context}

This section explores three key conceptual frameworks for understanding pedagogical issues in vocational teachers' development. It begins by addressing concepts of vocational knowledge to identify what it is that vocational teachers need to refresh and learn to maintain their expertise. To enable the exploration of key elements of effective pedagogy for vocational teachers, the discussion then moves to explore the concept of expertise and within this, models of professional learning. Finally there is a brief discussion on how vocational teachers know and the debates as to where knowledge is said to reside are explored. Discussed within these sections is the importance of context for professional learning.

\section{Understanding vocational knowledge: what teachers need to acquire}

The ways and mores of a vocation or occupation and thus the knowledge, skills and attributes that vocational teachers pass on to their students in learning settings are complex, complicated and multiplicitous. In starting to explore this further, this section focuses on the often-contrasted concepts of codified and tacit knowledge. Guile (2011) distinguishes these 
two types of knowledge as 'know how' which is situated, tacit knowledge and 'know that' which consists of de-contextualised, codified knowledge.

Codified knowledge is also deemed by Lave and Wenger (1991) as being decontextualised and Eraut (2000) describes it as public and propositional knowledge. Within these conceptions it is understood to be separated from practical activity and to be abstract in nature. The style that codified knowledge takes is that it is embedded in written form and as such can be presented to others in transparent and more easily understood ways. Codifying knowledge enables it to be transported across contexts. For vocational teachers and their students, codified knowledge is separated into disciplines and occupational areas and is found in course materials, assessment tools and accompanying text books, and other teaching and learning materials (Guile, 2011). However, this form of knowledge has inherent limitations. Gamble (2006) draws attention to this and suggests that codified knowledge enables a separation of thinking from execution. It divorces the 'know that' from the 'know how'. However, even given its limitations, within the realm of the teaching and learning of vocational knowledge and skills, it forms a distinct and influential aspect of what vocational teachers use and deploy in their teaching of students. A further limitation however, is that once codified, knowledge becomes static and thus loses its currency fairly rapidly.

Distinct from this, tacit or un-codified knowledge makes up the significant majority of knowledge shared, used and applied in vocational settings. It is developed through practice Hordern (2014) and Kotzee (2012) describes it as being what individuals either know or can do when they take part in social practices. This suggests that there is something ethereal about tacit knowledge. It points to it being fluid, temporal and in motion (Broad, 2016) rather than fixed, tangible and stable. Supporting this conception and through contrasting codified and tacit knowledge, Polanyi (1967), who originally developed the concept of tacit knowledge, described it as that which we know but cannot tell. This in itself raises challenges for vocational teachers in that, as it cannot be told, it is problematic and not straightforward to turn this into learning experiences and teaching materials for students. However, the importance for vocational teachers, and their students' learning is captured by Livingstone and Guile (2012) who argue that tacit knowledge is becoming the most important form of knowledge in learning organizations and increasingly so for the production of new knowledge. It is imperative, if teachers are to ensure that their students are conversant with current 
workplace practices, for them to capture and then recontextualize for learning contexts, this newly formed tacit knowledge.

The problems of viewing these two forms of knowledge as distinct from each other is often highlighted in the literature and Guile (2011) suggests that theoretical and practical concepts of knowledge, rather than being separate, have a mediated relation to one another. A practical example of the inherent problems of separating 'know that' from 'know how' can be seen in the processes involved in how to teach someone to tie a shoelace; "A brief list of all that is involved in tying a shoelace would overwhelm a learner." Duguid (2012: 151). Rather, the better approach would be to show the person in practical terms how to tie a shoelace and perhaps support this with some theoretical constructs in the form of an aide memoire or diagrammatic aid. Nevertheless, it is important to distinguish between codified and tacit knowledge and to recognize that both forms of knowledge present distinct problems for vocational teachers in bringing vocational expertise to the classroom settings of students. Emerging from these differing conceptions of vocational knowledge and the interplay between the two, frames this chapter by highlighting the complexity of, and thus difficulty in, teachers ensuring that their occupational expertise is maintained.

\section{Understanding vocational expertise in the context of vocational teachers}

No single theory of learning, professional or otherwise, currently exists. Rather there are a multiplicity of varying and at times, competing theoretical positions (Russ-Eft 2011). Historically, these have been drawn from psychological positions such as behaviorism and cognitive theory (Billett 2001). More recently, concepts have emerged from social learning theory that recognize the importance of both the social aspects of learning, the importance of situatedness and that of the context in which learning occurs. Influential in this is the work of Lave and Wenger (1991) and their central concept of the vehicle for learning, 'communities of practice' in which individuals are shown to be able to learn through participating in shared activity.

These two conceptual approaches for understanding professional learning and the development of expertise have been crystallized into a dichotomy of theorizing, with cognitive psychology contrasted to social theories of learning. As a facet of social learning 
theory, Pelissier (1991) takes an anthropological approach and examines various dichotomies in the constructions of differences in approaches to, and understandings of, learning within education, drawing the distinction between practice and capacity. Others however, have challenged this dualism and accept that understanding expertise requires an understanding of the relationship between the mind and social conditions of learning (Billett 2001). This is also encapsulated in the work of Sfard (1998) who suggests two metaphors of learning; learning as acquisition and learning as participation. She warns however, of the dangers of favouring just one. In the former model, learning is seen as the individualistic learning of facts, knowledge and skills, in the latter as participation in communities and in social practices. The importance here is that, "Different metaphors may lead to different ways of thinking and to different activities. We may say, therefore, that we live by the metaphors we use." (Sfard 1998: 5). This suggests that the way in which learning is conceptualized will determine the approach taken. It is argued here that in terms of pedagogy for vocational teachers, that aims to ensure the continued development of expertise, participative approaches will serve to be the most effective. Indeed, as discussed earlier, collaborative and thus participative approaches appear to be the most useful way of organizing CPD for teachers. However, to be able to recontextualize this across contexts, new knowledge will need to be internalized so that teachers can recontextualize and transport it from occupational to learning contexts.

\section{How vocational teachers know}

These debates concerning the nature of vocational knowledge and the development of expertise, raises interesting ontological and epistemological questions concerning 'knowing' and how experts know. Within approaches to understanding knowledge, it is seen to reside either in the heads of individuals (psychological approaches), or, within social practices (social constructivist theories). As we have seen from the above, psychological explanations, drawn from cognitive perspectives, view knowledge as being held in the mind of individuals. Social constructivist explanations view it as being situated in contexts, shared between individuals and collaborative groups and distributed through networks.

Early conceptualizations of tacit knowledge align with psychological theories in viewing knowledge as residing internally within the individual, rather than externally in social 
practices. Both Canning (2008) and Kotzee (2012) explain that Polanyi, in his development of the concept of tacit knowledge and Schön (1991), in his use of tacit knowledge in understanding reflective practice held this position. Eraut (2000) also takes this line and discusses tacit knowledge in terms of personal knowledge. However, as explored above in the discussion of expertise, more recent conceptualizations have shifted understanding of tacit knowledge to a shared social conceptualization and to view knowledge as a network effect (inter alia, McArdle and Ackland 2007; Fox 2000).

The importance of this discussion for understanding learning and the development of expertise is explored by Collins (2007) who explains that within psychological and somatic approaches, it is generally accepted that learning is seen as independent of context and therefore as transferable, unproblematically, to a range of diverse contexts. However, Hager (2011: 22) states powerfully that, "It seems that skillful practice of occupations is both holistic and significantly contextual, rather than atomistic and context-free". Eraut (2000), even though he suggests that knowledge is held in the minds of individuals, reinforces the importance of context for learning and states that the learning context affects the knowledge acquired and if that knowledge is to be applied in a different context, it will need further learning or recontextualization.

Actor Network Theory (ANT) draws knowledge and learning together and views both as highly contextual with learning emerging out of distributed practice networks. One conception takes a geographical position and views learning as, "...activities [that] are organized across space and time and [that] are produced in social practice or within social practices." (Nespor 1994: 1). Similarly, Latour (1986) views knowledge as performative and argues that it is developed in networks through action. It is through engagement within these performative networks that learning occurs. Drawing on sociology of associations, he states, "If a dancer stops dancing, the dance is finished. No inertia will carry the show forward." (Latour 2007: 37). This raises particular issues for vocational pedagogy when these practices take place in occupational sites, geographically separate from classrooms and taught by vocational teachers who are also in the main divorced from the occupation. The main concern is how these separate geographical locations can be connected in performative ways.

In summary, the conception of vocational teachers' pedagogy presented here suggests that it is highly complex, heterogeneous and contextual. This suggests that uniform approaches 
to the CPD of teachers may not be beneficial. Pedagogical approaches used need to enable vocational teachers to connect teaching environments, geographically and conceptually separated from where vocational knowledge is developed in networks, to occupational sites. It is suggested here that nature of vocational knowledge and of the development of expertise should be understood as residing both within these performative networks and in the heads of teachers as they work to learn and develop and then contextualize this for consumption by students in classrooms and learning settings.

\section{Researching vocational teachers' pedagogy}

The findings presented here are drawn from a study that sought to understand in practical terms, the practises that vocational teachers engage with to maintain and develop their vocational expertise. To capture the complexity described above, a material-semiotic approach, Actor-Network Theory (ANT) was adopted. A rallying call in ANT is to 'follow the actor' (inter alila, Latour 2007; Latour 1987; Callon, 1986) and led mainly to the use of ethnographic research methodology being used. The initial starting point for the research (see Broad, 2013, for further details) was by surveying vocational teachers to begin to understand their approaches to the continued development of expertise once qualified. This was followed with in-depth interviews with vocational teachers and the chairs of two professional associations, the Association of Hairdressers and Therapists (AHT) and the Association of Painting Craft Teachers (APCT). The AHT was subsequently followed through participant observation. Further in-depth interviews were conducted with the AHT teachers and other actors.

\section{Examining the pedagogical approaches adopted by vocational teachers}

The research approaches adopted, described in the previous section, enabled the capturing of the pedagogical practices of teachers on the ground, as they happened. Their recollections of their experiences also allowed a deeper and richer understanding to emerge. Key themes 
emerging was the importance that teachers place in maintaining their expertise, the varied and myriad ways in which they ensured that they kept up-to-date with their specialist vocational area, and the perceptions they held that their activities enhanced the learning experiences of their students.

\section{The importance of occupational expertise}

The maintenance and development of occupational expertise is seen by teachers to be crucial to their teaching role. No matter the subject or occupational area taught, or the contractual arrangements of the teacher, they all stated that it was important to some extent to maintain and develop their vocational expertise, with none of the sample seeing developing occupational expertise as not important. Within this, the majority of 64 (83 percent) saw it as very important. The remaining 13 (17 percent) saw it as important (Table One below).

Table One: Importance to teachers of maintaining and developing subject expertise

\begin{tabular}{|l|rr|}
\hline Answer Options & Response & Response \\
Percent & Count \\
\hline Very important & 83.1 & 64 \\
Important & 16.9 & 13 \\
Not very important & 0.0 & 0 \\
Not important at all & 0.0 & 0 \\
\hline answered question & & 77 \\
\hline
\end{tabular}

This importance is echoed in the amount of time teachers report devoting to CPD activities to maintain their occupational expertise, as opposed to for other reasons. More than half said maintaining and developing occupational expertise was the most frequent reason for CPD activity. 


\section{How teachers develop and refresh occupational expertise}

Vocational teachers use a range of activities to develop occupational expertise. The first activity reported here, short courses and workshops, were a frequent activity. However, these proved to be either very useful or of little value. Thirty-eight teachers (51 percent) reported that they had attended short courses and 46 (62 percent), had attended occupationally relevant workshops, which are short, often half day or one-day events.

\section{Courses and workshops}

Often these courses and workshops are viewed as not helpful by teachers because they cannot easily identify commonality between the subject matter of these events and their dayto-day practises as vocational teachers. An example was offered by three teachers in different vocational areas, employed at different colleges of internally provided safeguarding courses. One teacher of painting and decorating found it helpful because of the nature of the students he taught and that there had been "a serious problem" that he did not feel equipped to deal with. The course suggested a range of practical strategies. Two other teachers, one in applied sciences and the other business management, both teaching mature students, found little value in the course. The applied sciences teacher said:

The last one we did as far as I can recall, we spent a lot of time talking about how the new student disciplinary procedures were to be implemented. And, a lot of it was not appropriate [for my subject] anyway because of the nature of our students.

There are difficulties in pitching CPD courses at the appropriate level to teachers who have a wide range of knowledge and experience. It is also problematic when the audience is made up of teachers drawn from a wide range of subjects who also teach their subjects at varying levels. One often used solution is to generalize course content so that it 'fits' with as wide a range of circumstances as possible. However, this sets its own challenges, explained again by the applied sciences teacher: 
It wasn't really relevant for lots of the stuff I mean bits of it were, but most of it wasn't and it was done in a very fluffy way. Not very specific and bits and pieces like that.

Teachers found value in workshops that enabled them to network with and fold across to the occupational world. Why these courses and workshops are more beneficial than those provided by organizations is that they enable teachers to access expertise. The early years teacher discussed how she was able to listen to Tina Bruce (an academic consultant in early years and childhood studies), who she described as, "One of the leading lights in early years, she is amazing." The carpentry teacher had attended a week-long course provided by a tool manufacturer on making a Windsor chair which he described as being challenging but rewarding:

But the amount of work you have to do was quite incredible. To have a chair completed from you know, wood. [...] And that's a nice incentive and a great push, but they were long days.

He also explained that he was afforded opportunity to learn new techniques which he had not used when working in the occupation:

It was covering techniques that I haven't had experience of myself in my woodworking career, one of them being steam bending. [...] The other part of it too, was wood-turning which I haven't done much of.

\section{Learning with students and colleagues}

Teachers commonly liaised with manufacturers and in particular learnt alongside students. In response to the survey, 21 (28 percent) of the teachers learnt from participating in guest speaker events organised for students. The hairdressing teacher at interview and two AHT teachers also described the use of student training events. The construction teacher also explained this use of student training events:

I would much prefer to have people come to them and it's what we have done, had specialists come in, delivering say new technology in laser levels and things like that. 
Teachers also independently access manufacturer training. An example was offered by the applied sciences teacher who attends seminars and conferences organized by his professional association where much of the content is supplied by manufacturers:

[named manufacturer] they are going round the country giving free talks [...] So you turn up and listen to that

\section{The use of professional associations}

Professional associations play a significant role in the maintenance and development of occupational expertise for teachers. Twenty-six (60 percent) teachers surveyed were active in a professional association. The activities provide by these include student competitions, seminars, meetings and specialist occupational publications.

One of the main forums for collaborative learning through professional associations is student competitions and are central activities for both the AHT and the APCT. The benefits for teachers was described by a AHT hairdressing teacher as:

You see the changes and the styles changing and the fashions and the colour trends coming through.

Another AHT hairdressing teacher commented that she always learns something new at hairdressing competitions and explained how these competitions would tend to broaden her experiences of different approaches and techniques and said:

I've not seen that tool used in that way before. So I've taken some photographs and I'm going to go and get that tool when I get back.

She further explained that this form of learning, learning by watching and seeing, complements well the practical nature of the occupation.

Professional associations also offer seminars and meetings and the ACPT in the main organizes its meetings around CPD events and hold what the ACPT chair described as, "Saturday craft practical weekends." where manufacturers run workshops on their products and latest decorating techniques. The applied sciences teacher also described evening talks he had attended through his professional association: 
That [showing leaflet] is an evening 'do' which is promoted by [... the] Association

and it will be an hour's talk and we can go down there to the Royal Society of Medicine and we give up an evening to learn about topics

He also described 'peer review' events where a group of practitioners would come together to discuss a specific area that they had difficulties with. These were self-selecting and selforganised events that would happen as a one-off or a small series.

\section{Improving pedagogic practice}

The key driver for ensuring that vocational expertise is continued to be developed is that vocational teachers consider that it improves their own pedagogic practice, it makes them better teachers. One reason centres on their concerns about their credibility as professionals, within an occupational or subject area. The early years teacher said:

[...] because with the teaching, you have got to get it right, because especially at level three and foundation degree, they'll all go away and say 'actually I think you'll find you are wrong' the law says this or something, so, probably that is a personal challenge as a teacher to get it right.

The applied sciences teacher explained the importance of keeping up-to-date for his teaching. He began by saying that he could, if he wished to, sit back and produce the same materials for his students every year. For him however, it links to his interest in the occupational area. He said, "If you are interested and enthusiastic, you have to take a few opinions on board and you have to inform your students."

His concern was with being topical and au fait with current industry practices and said:

Because if you don't know what is going on in industry then you are out of date and if you are out of date, then that is less relevant to your students who you need to pass information on to.

The construction teacher was concerned with how best he could ensure that his students were better prepared for, "the real world" of the construction industry. He could identify very clear links between his ability to do this, and him keeping abreast of current trends and 
new technologies within the occupation. He then linked this to curriculum design and ways of stretching his students' occupational knowledge and said:

I'm thinking ahead [...] in the second year when they have all the work done, to perhaps do something different, whether it's a bit of veneer work, whether its curved work where you know, we use vacuum bags, or some steam bending [a technique he had recently learnt on a course]

Occupational CPD opportunities also enrich conversations that vocational teachers have with students. The graphic design teacher explained this as, "You can just talk about this nature or that nature of the work". Similarly, the applied science teacher stressed the importance of working within the occupational area and that it enabled more informed discussions with his students. He said, "And it's good to be able to turn round to students and say 'when I was in practice the other day, I saw blah'..." Likewise, the construction teacher could also identify how, through conversations based on his recent CPD experiences, he could improve the experiences of his students. For him, this meant sharing his experiences with the students and entering into professional dialogs by discussing his recent experiences and asking such questions as, "What do you think?"

\section{Discussion: The pedagogy of vocational teachers}

This section draws on the findings presented above and explores the defining characteristics of effective vocational teachers' pedagogy, as employed by teachers, to maintain and develop occupational expertise. It is acknowledged here that this is a complicated and complex process because much of what teachers need to access is shared and developed in contexts distant from the contexts they inhabit as teachers. Compounding this for those researching this phenomenon is that their activities are also largely hidden. However, the study presented here has made the practises of vocational teachers as they strive to maintain their expertise visible. In this section, the three elements of effective teacher pedagogy are discussed and examined: a) teacher agency; b) relational networks; and c) hidden pedagogical practices. 
The findings show that vocational teachers act with agency in identifying opportunities to maintain and refresh their occupational expertise and in shaping the pedagogical approaches to activities. They self-determine these activities based on what opportunities are afford them and those they find value in. They find value in activities that bring them closer to and enable them to engage more fully and firsthand with their original occupation. Returning to understandings of the development of expertise and professional learning, these teachers are adopting and preferring pedagogical approaches that favour active participation and involvement in learning processes. This approach to professional learning is suggested by Boud and Hager $(2011 ; 26)$ as more potentially useful and argue for, "a shift from use of acquisition and transfer to metaphors, such as participation, construction and becoming, that imply [...] active involvement..." and link this to concepts of teacher professional agency. They highlight that dominant metaphors of learning, of acquisition and transfer, turn the focus of professional development from outputs, the benefits, to inputs, the activity. This in turn leads to professional autonomy and agency being somewhat diminished and undermined. Congruent with this, the findings here show that vocational teachers find more benefit in participatory activities, rather than acquisition and sedentary approaches provided for them by employing organizations. They describe these as "fluffy" and not particularly relevant to the own pedagogic practice with their students.

These debates suggest a structure/agency dichotomy in teacher professional pedagogy. The debate however, is not solely concerned with structure/agency dichotomies but also concerned with networks. Mulcahy and Perillo (2010) remind that agency is distributed across various entities. Vocational teachers are influenced by the networks where vocational knowledge and skills are enacted into being, where they network with the tools, ideas and mores of the vocational area and it is to these particular networks that we now turn.

\section{Relational networks}

In contrast to the pedagogical approaches of organisations in the planning and execution of vocational teachers' professional development, they find the most benefit in activities that enable them to cross boundaries and to network with their original occupation in authentic and practical ways. The pathways that vocational teachers follow and the networks that they 
use are multiplicitous and heterogeneous. They vary from teacher to teacher, shaped by the opportunities presented and by their particular development needs. Some of these professional development networks are bounded by the organization with teachers working alongside both students and colleagues to develop expertise. Much of what is shared within organisations is manufacturer knowledge. Within the literature, the use of manufacturer provided opportunities is known and Lloyd and Payne (2012) report that for hairdressing teachers, manufacturers provide ample opportunities for teachers' development. The research here shows that teachers also take advantage of opportunities provided by manufacturers for their students. In addition, they also share learning with colleagues when one has attended a manufacturer training event. They network to manufacturers which enables them to connect to new product knowledge and keep abreast of the latest techniques, materials and tools. On occasion, these manufacturer opportunities take them outwith the organization, to seminars and courses provided by manufacturers and experts.

By far the most important form of networking for maintaining and refreshing occupational expertise is that provided by professional associations. They enable teachers to come together with other teachers, with practitioners and with experts in the occupational area. Orr (2013; 378), drawing on the work of Wenger, explains that mutual engagement in shared learning ventures enables the sharing of, "shared routines, words, tools, ways of doing things, stories, gestures, symbols, genres, actions and concepts" Through this, they are able to take part in the processes of new knowledge production, which it is contended here, is developed through shared practice, and to capture this, recontextualizing it for use within their own classrooms and learning sites. They can be seen to be part of a vocational teachers' extended community of practice. These communities of practice are, "... in part systems of relations among persons." (Lave and Wenger 1991: 53)

The importance of networking into the original industry has been highlighted by Smith and Rahimi (2011) who report that teachers involved in student competitions state this as one of the key benefits of involvement. These networks mediate between new knowledge and skills and classrooms with the teacher acting as a bridge between the two, bringing them together through their own learning of this new knowledge. This sets up a network of relations that extend beyond the teacher and connects powerfully with the learning and development of their students. 


\section{Issues of hidden pedagogy}

Emerging from the findings is that teachers perceive that their professional development activities enhance the learning of their students. This happens because these activities develop their pedagogic practice by refreshing the knowledge, skills and ideas they are able to share with their students. It gives them credibility with students, it helps to maintain their enthusiasm and thus maintains their confidence as vocational experts. Their professional development activities enable them to engage students in discussions about practice which in turn brings them closer to the occupational area they are studying. Through this process, teachers recontextualize vocational knowledge, turning it from a productive to a learning function (Moodie and Wheelahan 2012). This process of recontextualization is a process with inherent complexity and is not a straightforward knowledge transfer from one context to another. Evans et al (2010) describe the recontextualization process as chains forged by practitioners and as multi-faceted pedagogic practice. According to Wheelahan (2007), part of this process of recontextualization is that of selection and vocational teachers select the knowledge that they carry to vocational learning contexts.

Despite this complexity, the way in which vocational teachers' professional development is currently conceptualized and understood means that there is a lack of focus by employing organizations on both the development of occupational expertise for teachers and the benefits it presents to vocational students' learning. This issue however is not constrained to vocational teachers in England. Köpsén and Andersson (2017: 80) found in a study of Swedish vocational teachers' engagement with vocationally focused CPD, that they also faced institutions barriers to engagement such as, "managements' lack of interest or financial support". Due to what appear to be insurmountable difficulties, a generic approach tends to be adopted within organizations, with CPD workshops designed to meet a range of pedagogic needs. A potential concern with a generic approach to the development of pedagogic skills is highlighted by Fisher and Webb (2006: 342) who argue that current self-conceptions of teachers are not as 'subject' specialists but as "...a Jack/Jill of all trades". The reason for this is that the activities that teachers engage with to develop their occupational expertise are largely hidden from others. They go about this largely in their own time. They join in with colleagues after teaching has finished. They learn alongside students through collaboratively 
engaging with manufacturers. They join others outside of the organization and come together through professional associations in self-determined and self-selected communities of practice, sharing new knowledge and skills away from the organization. Nerland and Karseth (2013) in their study of professional associations, use the concept of 'knowledge work' as a way of describing and understanding how professional associations manage and standardize knowledge in their field. However, the findings presented here strongly suggest that vocational knowledge resists standardization and that the role it serves for vocational teachers is to enable them to access, share and develop knowledge.

\section{Concluding remarks}

Through exploring how vocational teachers, through their self-determined and self-selecting pedagogical approaches to the maintenance of their vocational expertise, this chapter sheds light on how they manage the in motion and circulatory nature of vocational knowledge. New technologies, new approaches and techniques are continually developed in and through workplace practices. In order to ensure high quality learning experiences for their students, vocational teachers need to keep abreast of these changes. The chapter began by conceptualizing vocational knowledge, which teachers attempt to capture through their CPD activities, and expertise and professional learning. This illuminated the complexity of vocational knowledge and thus the challenges that teachers face in maintaining their expertise in boundary crossing across geographical contexts and in recontextualizing knowledge from a learning to a productive function.

The findings presented here captured the pedagogical practices of vocational teachers and illuminate the main characteristics of effective pedagogy that are a), teacher agency; $b$ ) relational networks; and c) hidden pedagogical practices. Through this, the chapter set out to inform ways of thinking in relation to how teachers can best be supported in their endeavours to both maintain their vocational expertise and in using this to enhance the learning experiences of their students. It is argued here that those tasked with organizing and supporting the CPD of vocational teachers appreciate the complexity and heterogeneity of 
practice highlighted here. It is also suggested that the ways in which teachers maintain their expertise, predicated by the theoretical concepts presented here, through the sharing of practice with others, be taken account of when designing learning opportunities for vocational teachers. 


\section{References}

Andersson P, Köpsén S (2015). 'Continuing professional development of vocational teachers: participation in a Swedish national initiative'. Empirical Research in Vocational Education and Training 7 (1): 7.

Billett S (2001) Knowing in practice: Re-conceptualising vocational expertise. Learning and instruction 11 (6): 431-452.

Billett S (2011) Vocational Education: Purposes, traditions and prospects. Springer, London

Boud D, Hager P (2011) Re-thinking continuing professional development through changing metaphors and location in professional practices. Studies in Continuing Education, 34 (1): $17-30$

Broad J (2013) Doing if for themselves: A network analysis of vocational teachers' development of their occupationally specific expertise. Thesis, Institute of Education, University of London

Broad J (2016) Vocational knowledge in motion: rethinking vocational knowledge through vocational teachers' professional development. Journal of Vocational Education \& Training 68 (2): 143-160

Callon M (1986) Some elements of a sociology of translation: domestication of the scallops and the fishermen of St Brieuc Bay. In: Law J (ed), Power, action and belief: A new sociology of knowledge. Routledge, London

Canning R (2008) Reflecting on the reflective practitioner: muddled thinking and poor educational practices. Paper presented at UCET annual conference, Birmingham, 7-9 November 2008

Collins H (2007) Bicycling on the Moon: Collective Tacit Knowledge and Somatic-limit Tacit Knowledge. Organization Studies 28 (2): 257-262

Day C (2002). 'Revisiting the purposes of continuing professional development'. In: G. Trorey G, Cullingford, C (eds), Professional development and institutional needs (pp. 51-78), Ashgate publishing limited, Aldershot

Day C (2017). 'Competence-based Education and Teacher Professional Development'. In Mulder, M (ed), Competence-based Vocational and Professional Education: Bridging the Worlds of Work and Education (pp. 165-182), Springer International Publishing, Cham

Duguid P (2012) 'The Art of Knowing': Social and Tacit Dimensions of Knowledge and the Limits of the Community of Practice. In: Livingstone DW, Guile D (eds) The Knowledge Economy and Lifelong Learning: A Critical Reader Vol 4, Sense, Rotterdam

Eraut $M(2000)$ Non-formal learning and tacit knowledge in professional work. British Journal of Educational Psychology 70 (1): 113-136

Evans K, Guile D, Harris J, Allan H (2010) Putting knowledge to work: A new approach. Nurse Education Today 30 (3): 245-251

Fisher R, Webb K (2006) Subject specialist pedagogy and initial teacher training for the learning and skills sector in England: the context, a response and some critical issues. Journal of Further and Higher Education 30 (4): 337 - 349

Fox S (2000) Communities of practice, Foucault and Actor-network theory. Journal of Management Studies 37 (6): 853-866 
Gamble J (2006) Theory and Practice in the Vocational Curriculum. In Young M, Gamble J (eds) Knowledge, curriculum and qualifications for South African further education. HSRC Press, Cape Town

Gamble J (2013) Why improved formal teaching and learning are important in technical and vocational education and training (TVET). Revisiting global trends in TVET: Reflections on theory and practice, 204

Goodson I, Hargreaves A (1996). Teachers' professional lives. Routledge, London

Guile D (2011) Apprenticeship as a model of vocational 'formation' and 'reformation': the use of Foundation Degrees in the aircraft engineering industry. Journal of Vocational Education \& Training 63 (3): 451-464

Hager P (2011) Theories of workplace learning. In M. Malloch M, Cairns L Evans K, O'Connor BN (eds) The SAGE handbook of workplace learning. Sage publications, London

Hargreaves A (1994). Changing teachers, changing times: Teachers' work and culture in the postmodern age. Continuum, London

Hodkinson H, Hodkinson P (2005). 'Improving schoolteachers' workplace learning'. Research Papers in Education, 20 (2): 109-131

Hordern J (2014) How is vocational knowledge recontextualised?. Journal of Vocational Education \& Training 66 (1): 22-38

Köpsén S, Andersson P (2017) Reformation of VET and demands on teachers' subject knowledge - Swedish vocational teachers' recurrent participation in a national CPD initiative. Journal of Education and Work 30 (1): 69-83

Kotzee B (2012) Private practice: exploring the missing social dimension in 'reflective practice'. Studies in Continuing Education 34 (1): 5-16

Latour B (1986) The powers of association. In: Law J (ed) Power, action and belief: A new sociology of knowledge. Routledge Kegan Paul, London

Latour B (1987) Science in action: How to follow scientists and engineers through society. Harvard University Press, Cambridge Massachusetts

Latour B (2007) Reassembling the social: An introduction to Actor-Network-Theory. Oxford Univeristy Press, Oxford

Lave J, Wenger E (1991) Situated learning: Legitimate peripheral participation. Cambridge University Press, Cambridge

Livingstone DW, Guile D (eds) (2012) The knowledge economy and lifelong learning: A critical reader Vol 4, Springer Science \& Business Media, Rotterdam

Lloyd C, Payne J (2012) Raising the quality of vocational teachers: continuing professional development in England, Wales and Norway. Research papers in education 27 (1): 118

McArdle K, Ackland A (2007) The demands of the double shift: communities of practice in continuing professional development. Journal of Vocational Education and Training 59 (1): 107-120

Moodie G, Wheelahan L (2012) Integration and fragmentation of post compulsory teacher education. Journal of Vocational Education \& Training 64 (3): 317-331

Mulcahy D, Perillo S (2010) Thinking Management and Leadership within Colleges and Schools Somewhat Differently: A Practice-based, Actor-Network Theory Perspective. Educational Management Administration \& Leadership 39 (1): 122-145

Nerland M, Karseth B (2013) The knowledge work of professional associations: approaches to standardisation and forms of legitimisation. Journal of Education and Work 28 (1): 123 
Nespor J (1994) Knowledge in Motion: Space, Time and Curriculum in Undergraduate Physics and Management. Knowledge, Identity and School Life Series 2. Falmer Press, Bristol

Orr K (2013) Cultures, colleges and the development of ideas about teaching in English further education. Research in Post-Compulsory Education 18 (4): 377-388

Orr K, Simmons R (2010). 'Dual identities: the in-service teacher trainee experience in the English further education sector'. Journal of Vocational Education \& Training, 62 (1), 75-88.Pelissier C (1991) The anthropology of teaching and learning. Annual Review of Anthropology 20 (1): 75-95

Polanyi M (1967) The Tacit Dimension. Doubleday, New York

Russ-Eft D (2011) Towards a meta-thoery of learning and performance. In: Malloch M, Cairns

L, Evans K, O'Connor BN (eds) The SAGE handbook of workplace learning. SAGE publications, London

Schön DA (1991) The reflective practitioner: How professionals think in action. Avebury, Aldershot

Sfard A (1998) On two metaphors for learning and the dangers of choosing just one. Educational researcher 27 (2): 4-13

Smith H, Rahimi MA (2011) Modeling of vocational excellence: an international perspective. Paper presented at the $14^{\text {th }}$ AVETR Annual Conference, Melbourne, 28-29 April 2011

Wheelahan $L$ (2007) How competency-based training locks the working class out of powerful knowledge: a modified Bernsteinian analysis. British Journal of Sociology of Education. 28 (5): 637-651

Wheelahan L, Moodie G (2011) The quality of teaching in VET: final report and recommendations. Australian College of Educators 